\title{
Residential electricity demand in Taiwan
}

\author{
Pernille Holtedahl, Frederick L. Joutz*
}

Department of Economics, The George Washington University, Washington, DC 20052, USA

\begin{abstract}
This paper examines the residential demand for electricity in Taiwan as a function of household disposable income, population growth, the price of electricity and the degree of urbanization. Short- and long-term effects are separated through the use of an error correction model. In the long-run, the income elasticity is unit elastic. The own-price effect is negative and inelastic. In an error correction framework, the short-run income and price effects are small and less than the long-run effects. Cooling degree-day effects have a positive impact on short-run consumption. We have used a proxy variable, urbanization, to capture economic development characteristics and changes in electricity-using capital stocks not explained by income. The variable provides significant explanatory power to the model both in the shortand long-run. We interpret it as controlling for economic development factors not captured by the pure income effect and we think it holds promise for explaining residential electricity consumption in other developing countries.
\end{abstract}

(c) 2003 Elsevier B.V. All rights reserved.

JEL classifications: $\mathrm{Q} 41 ; \mathrm{C} 31$

Keywords: Electricity demand; Error correction; Urbanization; Developing country

\section{Introduction}

In the 40 years spanning the period 1955-1995, residential consumption of electricity in Taiwan increased from 257 to $26144 \mathrm{GWh}$. During the same period the economy underwent a rapid process of economic development and modernization. Aggregate household disposable income increased from 22438 to 5003970 NT\$ million. In real per capita terms that is equivalent to a 10 -fold increase. The Taiwanese economy was predominantly rural in the 1950s, while today it relies on

\footnotetext{
*Corresponding author. Tel.: + 1-202-994-4899; fax: +1-202-994-6147.

E-mail address: bmark@gwu.edu (F.L. Joutz).
} 
a world class manufacturing sector to produce technology-intensive goods. The proportion of the population living in cities has grown by more than $150 \%$ since the early 1950s. Nearly $60 \%$ of the population lives in cities with populations greater than 100000 inhabitants. The purpose of this paper is to examine the demand for residential electricity during this period of economic development.

There have been numerous empirical studies of electricity demand in industrialized (Western) countries. However, energy demand models from a developing country perspective may require a different framework. One potential difference is that economic growth and structural change associated with rapid development suggest that income and price elasticities will not be stable.

This study modifies the electricity demand model traditionally used in the literature for industrialized countries for the case of Taiwan. We made use of cointegration and error correction procedures. The degree of urbanization is used as a proxy variable for the extent of economic development that has occurred in Taiwan.

The paper is organized into five sections. The first section discusses the modification of typical electricity demand models for a developing country case. It attempts to explain both short-run and long-run behavior. Second, we present the data used in the study. Third, the econometric issues and time series properties of the data are examined. The model of electricity demand and econometric results are presented next, while the fifth section summarizes the findings of the paper.

\section{A general model of electricity demand for developing countries}

\subsection{A brief review of residential electricity demand models}

Residential electricity consumption can be expressed in general as a function of economic factors, $X_{t}$, and the stock of electrical energy-using equipment, $K_{t}$.

$\mathrm{kWh}_{t}=F\left(X_{t}, K_{t}\left(X_{t}\right)\right)$

The two variables can have independent and interdependent impacts on electricity demand. The capital stock of energy using equipment can be broken down into two types. The first satisfies the demand for daily energy services: lighting, refrigeration, cleaning and entertainment. The second relates to seasonal weather patterns, which can affect the demand for heating and cooling services.

In the short-run, the demand for electricity will be constrained to changes in the utilization rates given the fixed stock of electricity-using appliances. The dependence of capital stock on economic factors only holds in the medium- to long-run; beyond the short-run, the stock of appliances is flexible and can respond to changes in relative prices and income.

Fisher and Kaysen (1962) suggested a two-stage model. Consumption in the short-run (the first stage) depends on two variables: income, $Y_{t}$, and the price of electricity, $\mathrm{PE}_{t}$, and is given by

$$
\mathrm{kWh}_{t}=u_{t} * K_{t}=u_{t}\left(Y_{t}, \mathrm{PE}_{t}\right) * K_{t},
$$


where $u_{t}$ is the utilization rate(s) of the appliance stocks. In the second stage (the long-run), Fisher and Kaysen tried to explain the factors affecting the capital stock. Their (saturation) model used the growth rate in appliance stocks regressed on population, expected income, marriages, expected energy prices and the number of wired households. The measurement of capital stock was problematic. Fisher and Kaysen warned that the quality of the data ranged 'from somewhat below the sublime to a bit above the ridiculous.' and 'No results can be better than the data on which they are based.' (p. 27).

Taylor et al. (1984) summarized the results from research using the two-stage framework and found that there was an improvement in the results relative to a static model. However, they noted that until data on appliance stock improved, additional research would be hampered.

The estimation problems associated with the two-stage approach led researchers to develop an alternative procedure that avoided the use of equipment stock. In this alternative approach a distinction is made between actual consumption, $\mathrm{kWh}_{t}$, and long-run desired or equilibrium consumption, $\mathrm{kWh}_{t}{ }^{*}$. The latter is affected by the level of income, relative prices and other factors. To implement the procedure empirically, a partial adjustment framework is specified. There is a correspondence between the equipment stock and the desired consumption. Since actual equipment stocks will seldom be at their long-run equilibrium levels, actual consumption will differ from desired consumption. Consumers attempt to gradually bring actual consumption in line with their desired level according to this hypothesis or framework. They are only partially able to accomplish this in any time period. Nelson and Peck (1985), Nelson et al. (1989) and Harris and Lon-Mu (1993) provide excellent examples of this time series econometric approach.

\subsection{A modified model of residential electricity demand in developing countries}

The problem of correctly capturing or controlling for the electricity-using capital stock is magnified when working with developing countries. Obtaining estimates of the quantities and vintages of electricity-using equipment is more difficult. We propose an alternative means for conditioning demand on the capital stock. We believe that the level of urbanization is a reasonable proxy for electricity-using equipment since cities are electrified sooner than rural areas and are on the forefront of adopting modern household appliances.

Urbanization, our measure of economic development, is expected to increase the consumption of electricity. The reason is twofold. First, urbanization implies greater access to electricity, since households can be more easily connected to the grid. Second, those consumers who already had access to electricity before moving are likely to increase their consumption once they arrive in an urban setting. The increase in demand will take place through increased use of existing appliances (the utilization rate) and through the purchase of new ones (increased stock of capitalusing equipment). Examples of purchases include radios, televisions, fans, airconditioning and modern kitchen appliances, which may be a result of the increased exposure to the media and advertising typical of large cities. 
We have not found a similar use of urbanization in the time series approach similar to ours in previous research. However, the importance of urbanization measures has been noted by previous authors. Burney (1995) in a single year crosssection (by country) study of total electricity consumption has found that urbanization effects vary by country after controlling for per capita income and the share of industry in GDP. Lariviere and Lafrance (1999) model electricity consumption per capita for cities in Canada. They suggest that economic activity, demographic characteristics, meteorological factors and urban density are important explanatory variables of electricity consumption. Greater density is found to reduce energy consumption and should be considered in urban policy planning. Xiaohua and Zhenmin (2001) look at characteristics of energy consumption in rural Chinese households from the 1960s through the 1990s. They compare the shares of commercial energy consumption across different regions controlling for family income and heating degree needs. The share increases with economic development associated with access to different fuel sources and the construction of rural power supply networks.

Dahl and Erdogan (1994) briefly discuss the level of urbanization and industrialization in explaining oil demand in developing countries. However, their econometric models only use prices, income and population. Sheerin (1992) discusses economic growth and energy use as a factor input. The change in household energy use is decomposed into changes in appliance use, relative prices and economies of scale in delivering energy/power. Medlock and Soligo (2001) examine the effect of economic development (GDP per capita) on sector and intensity of energy enduse. They discuss the composition and level of aggregate consumption, but do not break it out by energy type. Below a certain level of income, the share of residential energy demand except transportation demand is found to rise; beyond that level it falls.

Obviously, the use and interpretation of a measure like urbanization will be influenced by a country's institutions and history. This measure may not prove useful in countries that have pursued policies aimed at electrifying rural areas and subsidizing electricity to reduce urbanization. Nevertheless, the level can capture aspects of economic development not explained by the pure income effect. We can rewrite Eq. (1) as follows:

$\mathrm{kWh}_{t}=F\left(X_{t}, \operatorname{Urban}_{t}\left(X_{t}\right)\right)$

where $X_{t}$ represents disposable income, energy prices and the number of customers. Thus, we modify the Fisher-Kaysen model using the following specification:

$\mathrm{kWh}_{t}=u_{t}^{*} K_{t}=u_{t}\left(Y_{t}, \mathrm{PE}_{t}, \operatorname{Urban}_{t}, \mathrm{CDD}_{t}\right) * \operatorname{Urban}_{t}\left(Y_{t}, \mathrm{PE}_{t}\right)$

In this paper, a general model for electricity demand in developing countries will be formulated as follows: 
$\mathrm{kWh}=f$ (Population, Income, Price $/ \mathrm{kWh}$, Price of Oil, Urbanization, Weather)

where the dependent variable $\mathrm{kWh}$ is residential electricity consumption; Income is real disposable income; Price $/ \mathrm{kWh}$ is the real price of electricity per kilowatt hour; Price of Oil is the world price of oil and is used as a proxy for substitutes for electrical energy; Urban is the degree of urbanization, expressed as the percentage of people living in urban areas with populations in excess of 100000 . Cooling needs as captured by Weather are important determinants in the short-run and utilization models.

Since electricity is a normal good (service), higher disposable income is expected to increase consumption through greater economic activity and purchases of electricity-using appliances in the short- and long-run. A rise in electricity prices ceteris paribus will lead to a fall in quantity demanded. Economic theory suggests that electricity purchases will depend on the relative prices of substitutes: natural gas and distillate fuel oil. However, the independent influences of alternate fuel prices may be rather small because of the response by suppliers and the constraints on consumers to switching fuels in the short-run. Natural gas is not appropriate in the case of Taiwan, since its consumption has been comparatively small and recent. Thus, we follow Kokklenberg and Mount (1993) and take fuel oil prices as our measure of alternative prices.

The specification of the model above treats the price of electricity, disposable income and urbanization as exogenous variables. However, it is possible that these variables are jointly determined. Our empirical approach tests whether these variables can be treated as weakly exogenous.

\section{The data}

Fig. 1 reveals the dramatic (exponential) growth in residential electricity consumption. In 1955, consumption was approximately $250 \mathrm{GWh}$; by 1995 it had grown 100 times to over $25000 \mathrm{GWh}$. Per capita consumption grew by nearly 45 times from 28000 to $1264000 \mathrm{kWh}$ (Fig. 2).

The degree of urbanization, measured as the percentage of the population living in cities with populations greater than 100000 , demonstrates the large structural changes taking place in the country during this period. Fig. 3 shows that in 1955 approximately $23 \%$ of the population lived in urban areas. This proportion had increased to nearly $60 \%$ by 1995; the fastest migration occurred from 1967 to 1977 when the proportion grew from $30 \%$ to over $45 \%$. Real disposable income per capita grew nearly 10 times between 1955 and 1995, from 19000 to 196000 NT\$. The base year is 1990. Fig. 4 shows a plot of disposable income. It took the first 15 years for real disposable income to double. During the first 3 years of the 1970s, income increased a further 20000 NT\$. However, the oil crisis and global recession in 1974-1975 led to a decline in income by more than 5000 NT\$ per person, 


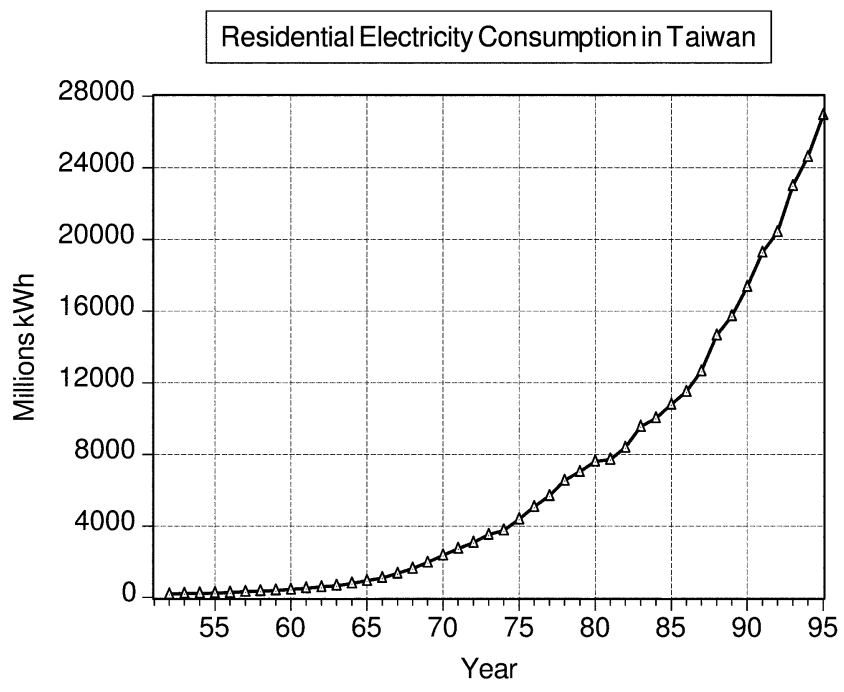

Fig. 1. Residential electricity consumption in Taiwan.

approximately $10 \%$ of total disposable income. After that the economy grew at a fairly steady pace with per capita income increasing from 50000 to 190000 NT\$ by 1995 .

Fig. 5 shows the price per kilowatt hour in real and nominal values. Prices fell in real terms by more than 50\% from 1955 to 1976, a period including during the oil shock of 1974 . At that time, more than $60 \%$ of the thermal generating capacity

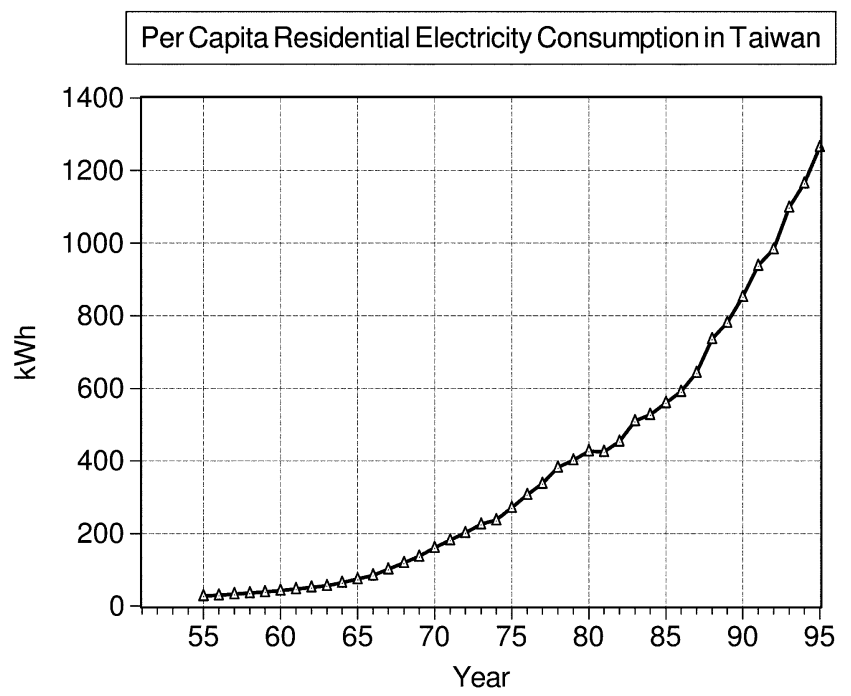

Fig. 2. Per capita residential electricity consumption in Taiwan. 


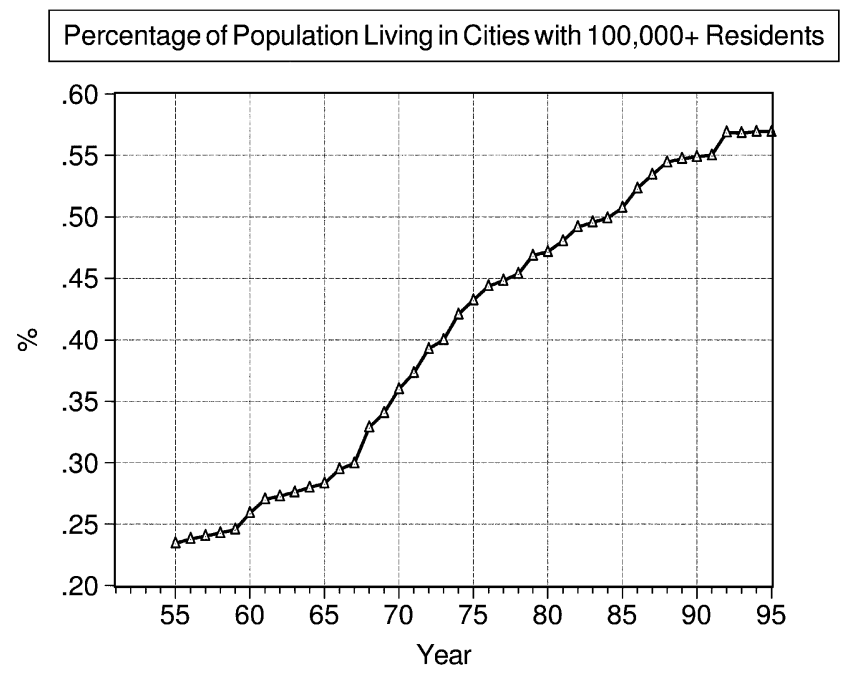

Fig. 3. Percentage of population living in cities with $100000+$ residents.

was from oil-fired systems. Taipower has since changed the fuel mix so that today less than 20\% is from oil-fired systems (Chien, 1997). In 1979 and 1980, the nominal price nearly doubled and the real price increased by more than $50 \%$. This was a component of the government's conservation policy measures taken in response to the sharp rise in international energy prices in the 1970s. Since 1982

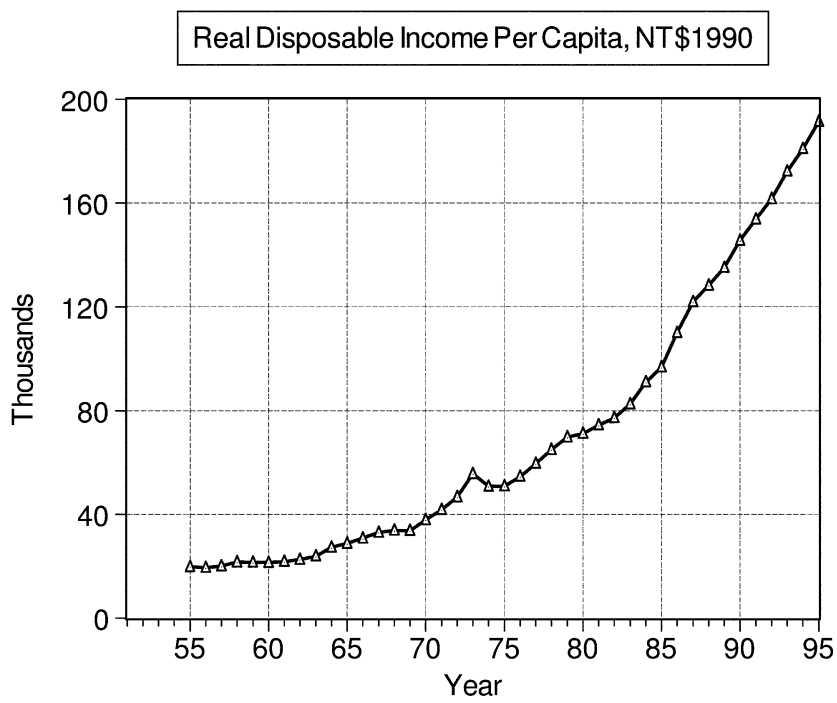

Fig. 4. Real disposable income per capita, NT $\$ 1990$. 


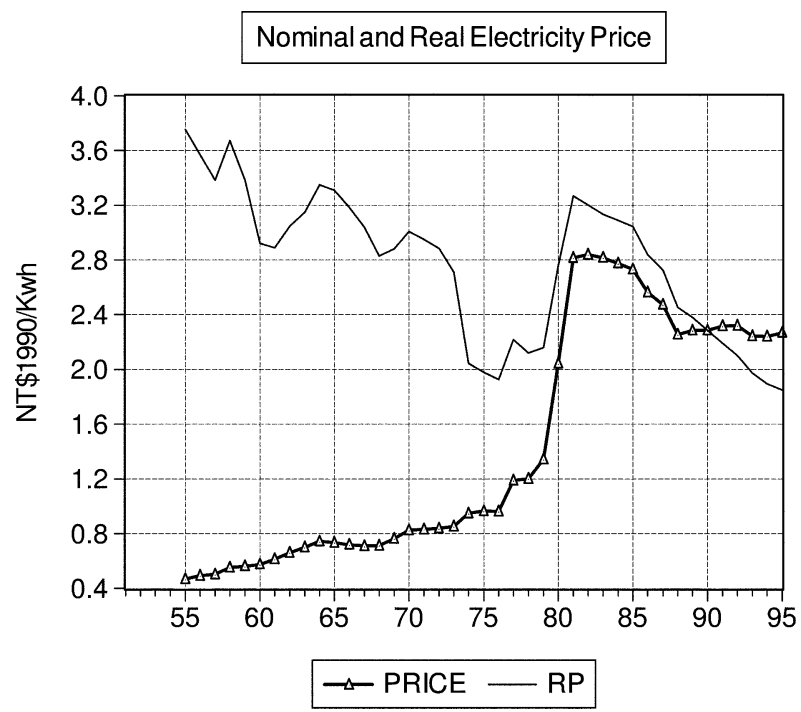

Fig. 5. Nominal and electricity price.

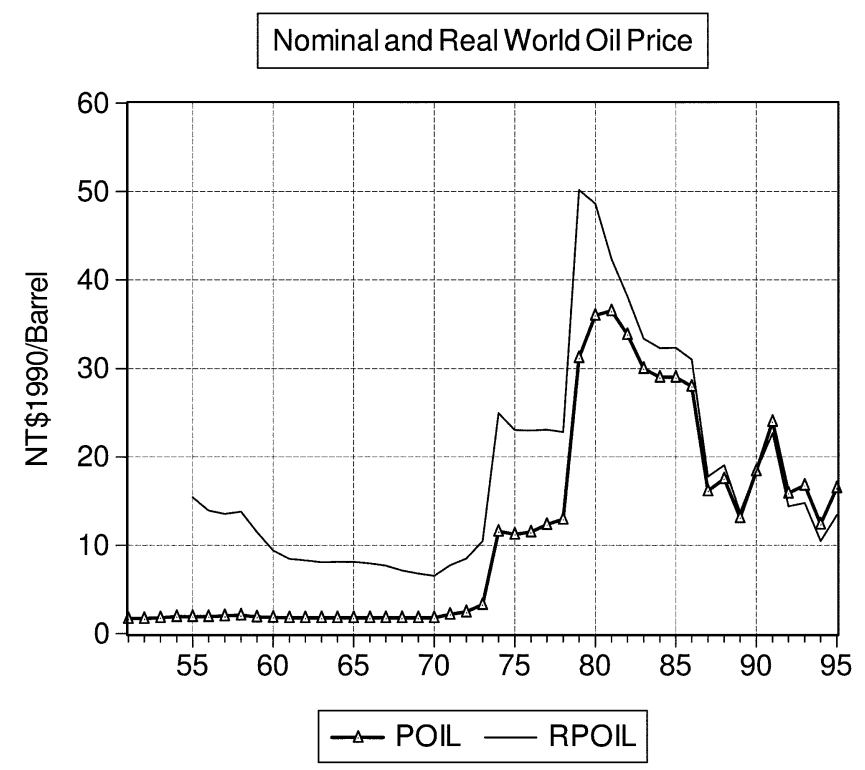

Fig. 6. Nominal and real world oil price. 


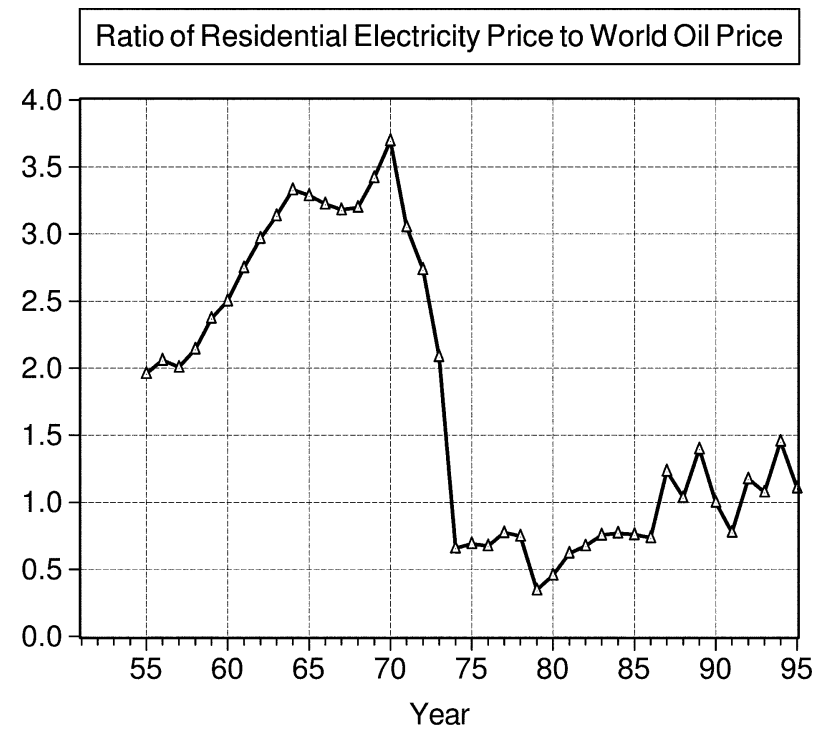

Fig. 7. Ratio of residential electricity price to world oil price.

the real price of electricity has steadily declined, while the nominal price has stayed between 2.0 and 2.8 NT\$ kWh (7-8 US $\varnothing$ ).

Real and nominal oil prices are plotted in Fig. 6. The relative price of electricity to oil is plotted in Fig. 7 (note that it does not include import tariffs or taxes). Initially, the price of electricity rose in relative terms until 1970, when it fell dramatically, by $66 \%$. From then on the two prices have stayed close to parity.

Monthly mean temperature data were obtained from the ROC Central Weather Bureau for the station in Taipai. This was converted to the annual number of cooling degree-days where the mean temperature exceeded either 74 or $80{ }^{\circ} \mathrm{F}$. Heating degree-day needs appeared to be negligible. Fig. 8 plots both cooling degree measures. The number of cooling degree-days using $74{ }^{\circ} \mathrm{F}$ averages approximately 600 , while the cooling degree-days using $80^{\circ} \mathrm{F}$ is approximately a quarter of this.

\section{Econometric modeling issues and results}

We employ the general-to-specific modeling approach advocated by Hendry (1986) and Hendry and Juselius (2000, 2001). The general-to-specific modeling approach is a relatively recent strategy used in econometrics. It attempts to characterize the properties of the sample data in simple parametric relationships that remain reasonably constant over time, account for the findings of previous models and are interpretable in an economic and financial sense. Rather than using econometrics to illustrate theory, the goal is to 'discover' which alternative theoretical views are tenable and test them scientifically. 


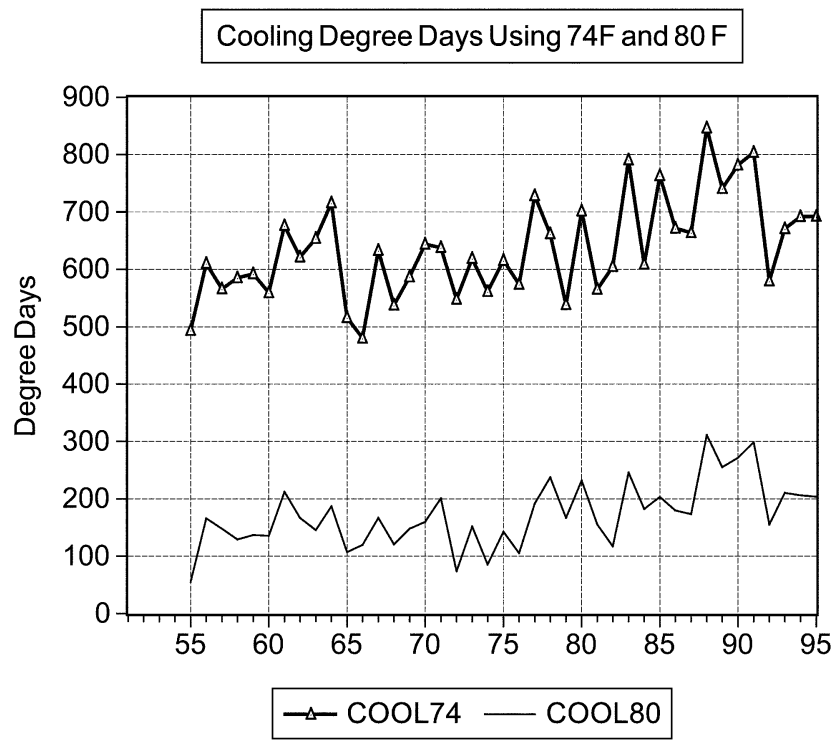

Fig. 8. Cooling degree-days using 74 and $80^{\circ} \mathrm{F}$.

The approach begins with a general hypothesis about the relevant explanatory variables and dynamic process (i.e. the lag structure of the model). The general hypothesis is considered acceptable to all adversaries. Then the model is narrowed down by testing for simplifications or restrictions on the general model.

The first step involves examining the time series properties of the individual data series. We look at patterns and trends in the data and test for stationarity and the order of integration. Second, we form a Vector Autoregressive Regression (VAR) system. This step involves testing for the appropriate lag length of the system, including residual diagnostic tests and tests for model/system stability. Third, we examine the system for potential cointegration relationship(s). Data series that are integrated of the same order may be combined to form economically meaningful series that are integrated of lower order. Fourth, we interpret the cointegrating relations and test for weak exogeneity. On the basis of these results a conditional error correction model of the endogenous variables is specified, further reduction tests are performed and economic hypotheses tested.

\subsection{Time series properties of the individual series}

Campbell and Perron (1991) provide rules (of thumb) for investigating whether time series contain unit roots. To begin, we estimate the following three forms of the augmented Dickey-Fuller (ADF) test where each form differs in the assumed deterministic component(s) in the series: 
Table 1

$\mathrm{ADF}(3)$ statistics testing for a unit root

\begin{tabular}{llllllllr}
\hline Order & \multicolumn{7}{l}{ Variable } & \multicolumn{7}{l}{} \\
\cline { 2 - 8 } & $\mathrm{kWh}$ & $\mathrm{kWhpc}$ & $\mathrm{Yd}$ & $\mathrm{Ydpc}$ & $\mathrm{Rp}$ & Rpoil & $\mathrm{Rpp}$ & Urban \\
\hline$I(1)-6$ & 1.01 & 0.76 & 9.97 & 7.64 & -1.04 & -0.19 & -1.44 & 6.32 \\
$I(1)-7$ & -2.82 & -2.31 & -0.52 & 0.39 & -1.78 & -1.29 & -1.37 & -1.74 \\
$I(1)-8$ & -1.01 & -1.86 & -3.24 & $-4.19^{*}$ & -1.49 & -1.21 & -1.48 & -0.07 \\
$I(2)-6$ & -0.62 & -0.54 & -2.00 & $-2.57^{* *}$ & $-3.78^{* *}$ & $-6.03^{* *}$ & $-6.18^{* *}$ & $-2.59^{*}$ \\
$I(2)-7$ & $-3.19^{*}$ & $-3.78^{* *}$ & $-5.24^{* *}$ & $-5.23^{* *}$ & $-4.05^{* *}$ & $-5.94^{* *}$ & $-6.12^{* *}$ & $-5.12^{* *}$ \\
$I(2)-8$ & $-4.35^{* *}$ & $-4.51^{* *}$ & $-4.63^{* *}$ & $-4.76^{* *}$ & $-4.00^{* *}$ & $-5.89^{* *}$ & $-6.05^{* *}$ & $-5.46^{* *}$ \\
\hline
\end{tabular}

The sample period for the ADF test was from 1959 to 1995. All variables are in natural logarithms with the exception of the urban variable. The first three rows, $I(1)-i$, present the ADF $t$-tests corresponding to tests for unit roots in the levels of the series. The last three rows, $I(2)-i$, report the ADF $t$-test results for testing whether the first difference has a unit root. A rejection implies that the first difference of the series is a stationary process. The identifier $i$ refers to Eqs. (6)-(8) in the paper, which are ADF regressions with no constant, a constant and a constant plus trend, respectively. The critical values for the $t$-tests at $5 \%$ are $-1.95,-2.95$ and -3.54 , respectively; at $1 \%$ they are $-2.62,-3.62$ and -4.23 , respectively. Rejections at the 5 and $1 \%$ critical values are denoted as $*$ and $* *$, respectively. The critical values for this table are calculated from MacKinnon (1991). A maximum of three lags was used in each test. The appropriate lag length was chosen by examining the autocorrelation function of the residuals.

$\Delta z_{t}=\alpha_{1} z_{t-1}+\sum_{i=1}^{P} \gamma_{i} \Delta z_{t-i}+\varepsilon_{t}$

$\Delta z_{t}=\alpha_{0}+\alpha_{1} z_{t-1}+\sum_{i=1}^{P} \gamma_{i} \Delta z_{t-i}+\varepsilon_{t}$

$\Delta z_{t}=\alpha_{0}+\alpha_{1} z_{t-1}+\alpha_{2} * t+\sum_{i=1}^{P} \gamma_{i} \Delta z_{t-i}+\varepsilon_{t}$

The $\varepsilon_{t}$ is assumed to be a Gaussian white noise random error and $t=1, \ldots, T$ (the number of observations in the sample) is a term for trend. In Eq. (6) there is no constant or trend. Eq. (7) contains a constant but no trend. Both a constant and a trend are included in Eq. (8). The number of lagged differences, $P$, is chosen to ensure that the estimated errors are not serially correlated.

The results from the unit root tests are found in Table 1. The first three rows test the null hypothesis that a series follows a unit root process or random walk. This implies it is non-stationary and (possibly) integrated of order one, $I(1)$, rather than $I(0)$. The second three rows test the null hypothesis that first differences of a series follow a unit root. If true, the researcher must difference the series twice to obtain a stationary process.

We find that for all series in Table 1 the null hypothesis of a unit root in the level cannot be rejected. There is evidence that income per capita is stationary, $I(0)$, for the ADF regression including a constant and trend term, $I(1)-8$. However, further testing suggested that the model with only a constant was the appropriate choice, 
I(1)-7. The slope coefficient of the trend term was insignificant. The tests for unit roots in the second differences are rejected, implying that the series are $I(1)$ and stationary in their first differences.

\subsection{The VAR system}

The function for electricity demand is specified to reflect the economic determinants and development from a predominantly rural economy to an urban industrial one.

$\mathrm{LkWhpc}_{t}=A_{t} \cdot \mathrm{LYdpc}_{t}^{\beta_{1}} \cdot \operatorname{LRp}_{t}^{\beta_{2}} \cdot \operatorname{LRPoil}_{t}^{\beta_{3}} \cdot \operatorname{Urban}_{t}^{\beta_{4}} \cdot \mathrm{CDD}_{t}^{\beta_{5}} \cdot e^{\varepsilon_{t}}$

where $\mathrm{LkWhpc}_{t}$ is the quantity of electricity consumed in billions of kilowatt hour, $\mathrm{LYdpc}_{t}$ is real disposable income in 1990 dollars, $\mathrm{LRp}_{t}$ is the real price of electricity per kilowatt hour, LRPoil $t$ is the real world oil price, Urban ${ }_{t}$ is the population in cities of 100000 or more and $\mathrm{CDD}_{t}$ is a measure for cooling degree-day needs. The $A_{t}$ term can include deterministic elements like trend(s) and dummy variables.

In the econometric analysis, we specify electricity consumption and disposable income in per capita terms. Also, the variables are transformed to natural logarithms with the exception of the urbanization variable, since it is already in percentage terms. Plourde and Ryan (1985) note the pitfall of modeling in double log form with its impact on elasticities and specification of the utility function. We tried models in levels and semi-log form, but were unable to obtain useful results; this may be due to the non-stationarity of the data.

We specify the VAR as a four variable system with a sample period from 1956 to 1995 . The model includes the log of the real world oil price, cooling degree-day effects, a trend term and dummy variable. Between 1979 and 1981, there were sharp increases in the energy price variables. On the basis of correspondence with officials from Taipower and the Energy Commission of the Ministry of Economic Affairs, we constructed a pulse dummy variable with a value of unity for those years and zero in all other years.

$Z_{t}=\Pi_{0}+\sum_{i=1}^{k} \Pi_{i} Z_{t-i}+\sum_{j=0}^{m} \Theta_{j} X_{t-j}+E_{t}$

where $Z_{t}=\left[\begin{array}{l}Z_{1 t} \\ Z_{2 t} \\ Z_{3 t} \\ Z_{4 t}\end{array}\right]=\left[\begin{array}{l}\text { Residential KWh per capita } \\ \text { Real price of electricity } / \mathrm{KWh} \\ \text { Real disposable income per capita (NT\$1990) } \\ \text { Urbanization }\end{array}\right]$

where $X_{t}=[$ Real price of oil Cooling degree days ]'

where last term, $E_{t}$, is a matrix of random disturbances assumed to be approximately normally distributed. 
Table 2

Lag length specification tests $\mathrm{F}$ and related statistics for the sequential reduction from the third-order VAR to the first-order sample period 1958-1995

\begin{tabular}{|c|c|c|c|c|c|c|}
\hline \multicolumn{4}{|c|}{ Null hypothesis } & \multicolumn{3}{|c|}{ Maintained hypothesis } \\
\hline System & $k$ & $L$ & $\mathrm{SC}$ & $\operatorname{VAR}(3,3)$ & $\operatorname{VAR}(3,0)$ & $\operatorname{VAR}(2,0)$ \\
\hline $\begin{array}{l}\operatorname{VAR}(3,3) \\
\operatorname{VAR}(3,0)\end{array}$ & $\begin{array}{l}76 \\
64\end{array}$ & $\begin{array}{l}612.65 \\
603.64\end{array}$ & $\begin{array}{l}-24.97 \\
-25.64\end{array}$ & $\begin{array}{l}\text { n.a. } \\
0.69668 \\
{[0.7453]} \\
(12,42)\end{array}$ & & \\
\hline $\operatorname{VAR}(2,0)$ & 48 & 594.23 & -26.68 & $\begin{array}{l}0.65113 \\
{[0.8923]} \\
(28,59)\end{array}$ & $\begin{array}{l}0.64572 \\
{[0.8327]} \\
(16,58)\end{array}$ & \\
\hline $\operatorname{VAR}(1,0)$ & 32 & 580.58 & -27.49 & $\begin{array}{l}0.79605 \\
{[0.7865]} \\
(44,63)\end{array}$ & $\begin{array}{l}0.87297 \\
{[0.6579]} \\
(32,71)\end{array}$ & $\begin{array}{l}1.1749 \\
{[0.3094]} \\
(16,70)\end{array}$ \\
\hline
\end{tabular}

The first four columns report the VAR models with the lags of the endogenous variables and the lags of the exogenous variable, the real oil price, the number of unrestricted parameters, $k$; the log likelihood statistic, $L$; and the Schwarz-Criterion, SC. The individual cells of the three columns containing the maintained hypothesis results show the approximate F-statistic for testing the null hypothesis in the first column against the maintained model, the tail probability associated with the F-statistic in square brackets and the respective degrees of freedom for the constrained parameters and the observations minus free parameters in parentheses.

The appropriate lag length for the VAR and cointegration analysis was determined using Wald F-tests and the Bayesian Schwarz Criterion (BSC). These measures compare the fit of the maintained model against reductions in the number of explanatory and predetermined variables. The original specification for the VAR begins with three lags of the endogenous variables and three lags of the real world oil price. Residual diagnostics suggested that there was no evidence of serial correlation of the residuals. Recursive analysis was performed on the system and it was found to be stable. Table 2 presents results from the lag length tests. The first test examines whether three lags of the oil price contributes to the model fit. They do not; the BSC declines from -24.97 to -25.64 . The F-test for the 12 restrictions and 42 degrees of freedom is 0.69 with an associated $P$-value of 0.75 .

The testing process is continued by dropping the third lag of the endogenous variables and then both the third and the second. The BSC reaches a minimum at a single lag. The Wald test is conducted for the maintained and all previous models in the right-hand panel; the conclusion is the same. We find that one lag of the endogenous variables and only the contemporaneous value of the real oil price provide the same explanatory power for the system as the models with more lags.

\subsection{Cointegration testing}

Cointegration tests are a multivariate form of integration analysis. Individual series may be $I(1)$, but a linear combination of the series may be $I(0)$. The error 
correction model is a generalization from the traditional partial adjustment model and permits the estimation of short-run and long-run elasticities.

The approach is based on the findings of Nelson and Plosser (1982), in which many macroeconomic and aggregate level series are shown to be well modeled as stochastic trends, i.e. integrated of order one, or $I(1)$. Simple first differencing of the data will remove the non-stationarity problem, but with a loss of generality regarding the long-run 'equilibrium' relationships among the variables.

Engle and Granger (1987) solve this filtering problem with the cointegration technique. They suggest that if all, or a subset of, the variables are $I(1)$, there may exist a linear combination of the variables that is stationary, $I(0)$. The linear combination is then taken to express a long-run 'equilibrium' relationship. ${ }^{1}$ Series that are cointegrated can always be represented in an error correction model. The error correction model is specified in first differences, which are stationary, and represent the short-run movements in the variables. When the error correction term, $\mathrm{ecm}$, is included in the model, the long-run, or equilibrium, relations are accounted for. The ecm term represents the deviation from the equilibrium relation in the previous period. For example, the growth rate of electricity consumption per capita would be a function of the growth rates in real disposable income per capita, real electricity prices, real world oil prices, the degree of urbanization and the error correction term. Lags of the independent and dependent variables would be included to capture additional short- and medium-term dynamics of electricity consumption. The advantage of the first difference model is that the specification is stationary so that estimation and statistical inference can be performed using standard statistical methods. The contemporaneous coefficients are interpreted as short-run elasticities.

The VAR system in Eq. (10) can be rewritten in matrix form:

$z_{t}=\prod_{0}+\prod_{1} z_{t-1}+\cdots+\prod_{k} z_{t-k}+\varepsilon_{t}$.

In our case $z$ is a $(p \times 1)$ vector of nonstationary $I(1)$ variables, where $p=4$. The $\Pi_{i}$ are $(p \times p)$ coefficient matrices at different lags. In this case, we are using only a single lag of the variables, and the real world oil price enters in restricted form as an exogenous variable. $\Pi_{0}$ is a $(p \times 3)$ vector of constant terms; it includes a constant, a time trend and a dummy variable for the 1979-1981 period. The matrix $(t \times p)$ of disturbances, $\varepsilon_{t}$, are assumed to be white noise. The system in levels can be transformed to one in differences and the error correction term without loss of generality.

$\Delta z_{t}=\Pi_{0}+\Gamma_{1} \Delta z_{t-1}+\cdots+\Gamma_{k-1} \Delta z_{t-k+1}+\Pi z_{t-k}+\varepsilon_{t}$,

where $\Gamma_{i}=-I+\prod_{1}+\cdots+\prod_{i} ; \forall i=1, \ldots, k-1, \quad$ and $\Pi=-I+\prod_{1}+\cdots+\prod_{k}$

The rank of the matrix for the level terms, $\Pi$, is of reduced rank when

${ }^{1}$ The issues are discussed in the introductory chapter by Doornik and Hendry (1992). 
Table 3

Cointegration analysis of the Taiwan residential electricity data

\begin{tabular}{|c|c|c|c|c|c|}
\hline Eigen value & 0.598 & 0.433 & 0.266 & 0.102 & \\
\hline Null hypothesis & $r=0$ & $r \leqslant 1$ & $r \leqslant 2$ & $r \leqslant 3$ & \\
\hline$\lambda \max$ & $36.48 * *$ & 22.69 & 12.38 & $4.33 *$ & \\
\hline$\lambda \max$ & $32.83 * *$ & 20.42 & 11.15 & $3.9 *$ & \\
\hline $95 \%$ critical value & 30.3 & 23.8 & 16.9 & 3.7 & \\
\hline$\lambda$ trace & $75.89 * *$ & $39.41 *$ & 16.72 & $4.33 *$ & \\
\hline$\lambda$ trace & $68.3 * *$ & $35.47 *$ & 15.05 & $3.9 *$ & \\
\hline \multirow[t]{2}{*}{$95 \%$ critical value } & 54.6 & 34.6 & 18.2 & 3.7 & \\
\hline & \multicolumn{5}{|c|}{ Standardized eigenvectors $\beta^{\prime}$} \\
\hline \multirow[t]{6}{*}{ Variable } & LkWhpc & Urban & LRYdpc & LRp & LRpoil \\
\hline & 1.00 & -3.31 & -1.57 & 0.15 & -0.18 \\
\hline & -0.23 & 1.00 & -0.29 & $-0.22 \mathrm{e}-03$ & $0.1 \mathrm{e}-05$ \\
\hline & 0.51 & -8.46 & 1.00 & -0.42 & 0.11 \\
\hline & -3.49 & 11.81 & 14.38 & 1.00 & -6.70 \\
\hline & \multicolumn{4}{|c|}{ Standardized speed of adjustment coefficients $\alpha^{\prime}$} & \\
\hline LkWhpc & 0.081 & 0.113 & 0.007 & 0.003 & \\
\hline Urban & 0.015 & -0.068 & 0.018 & -0.0001 & \\
\hline LRYdpc & 0.100 & 0.041 & -0.178 & $-0.7 e-04$ & \\
\hline \multirow[t]{2}{*}{ LRp } & 0.084 & 1.055 & -0.085 & -0.003 & \\
\hline & \multicolumn{4}{|c|}{ Weak exogeneity tests } & \\
\hline Variable & LkWhpc & Urban & LRYdpc & LRp & \\
\hline$\chi^{2}$ & $8.98 * *$ & $5.07 *$ & $4.85^{*}$ & 1.27 & \\
\hline$P$-value & 0.003 & 0.024 & 0.028 & 0.25 & \\
\hline
\end{tabular}

The VAR is estimated over the period 1957-1995. It includes one lag of each variable and the contemporaneous value of the real oil price. A constant, trend and the dummy variable for 1979-1981 are entered in unrestricted form. The statistics $\lambda$ max and $\lambda$ trace are Johansen's maximal eigenvalue and trace statistics for testing for cointegration. The null hypothesis is in terms of the cointegration rank $r$. For example, rejection of $r=0$ is evidence in favor of at least one cointegrating vector. The adjusted statistics control for the degrees of freedom. The critical values are taken from Osterwald-Lenum (1992). The weak exogeneity test statistics are evaluated under the assumption that $r=1$ and are thus asymptotically distributed as $\chi^{2}$ with 1 degree of freedom if weak exogeneity of that variable for the cointegrating vector is valid.

cointegrating relationships exist. In that case it can be partitioned as $\Pi=\alpha \beta^{\prime}$ where $\alpha$ is the $(p \times r)$ matrix of speed of adjustment coefficients and $\beta$ is the $(p \times r)$ matrix of cointegrating vectors or long-run relationships. Cointegration testing and the maximum likelihood estimation of $\beta$ are derived from a series of regressions and reduced rank regressions.

Table 3 contains the results from the cointegration analysis. The first column gives the null hypotheses of more than $p-r=0,1,2$ or 3 cointegrating vectors. When there are no cointegrating vectors, $p-r=0$ and the model in differences is appropriate. We compare our results against the updated values in Table 2 of Osterwald-Lenum (1992). The results from the maximum eigenvalue and trace 
statistics indicate the presence of a single cointegrating relation. There is marginal evidence of possibly a second vector using the trace statistic, but we could not find sufficient evidence of a stable relationship nor are we able to provide an economic justification for including it.

The implied cointegrating relationship is obtained from the first row of the standardized $\beta$ eigenvector. We interpret it as the desired level of per capita residential electricity consumption.

$$
\text { LkWhrpc }=3.31 * \text { Urban }+1.57 * \text { LRYdpc }-0.15 * \text { LRp }+0.18 * \text { LRPoil }
$$

The tests for weak exogeneity can reveal if the implied disequilibrium in the cointegrating relation feeds back into a subset of the current endogenous variables. Individually, LkWhpc, Urban and LRYdpc reject the null hypothesis of no feedback. However, the real own price of electricity does appear to be weakly exogenous. Historically, the Taiwan Power Corporation has set prices according to economic and social/political criteria that may explain the statistical finding. These results imply that we can reduce the system to a three-variable VAR conditioning on the two energy price series.

Note that the electricity price and oil price coefficients are roughly equal and of opposite signs. We test for the relative price restriction along with the weak exogeneity of the real oil price and obtain the following reduction in the cointegration vector.

$$
\text { LkWhrpc }=3.91 * \text { Urban }+1.04 * \text { LRYdpc }-0.16 *(\text { LRp }- \text { LRPoil })
$$

The $\chi^{2}$ statistic with two degrees of freedom is 1.42 with a $P$-value of 0.42 , thus we cannot reject the restriction. The income elasticity is slightly greater than unity. An increase of $1 \%$ in urbanization leads to nearly a $4 \%$ increase in residential electricity consumption. An increase in the relative price of electricity of $1 \%$ leads to a decline in consumption of 0.16 ; demand is relatively inelastic. This estimate is reasonably close to the long-run own-price elasticity of demand in numerous other studies (e.g. Bohi and Zimmerman (1984), Dahl (1993), Halvorsen (1975), Espey (1999), Nelson and Peck (1985) and Nelson et al. (1989)).

Since the major focus of our paper is residential electricity demand and the possible relationship with urbanization, we test the restriction that income and energy prices are jointly weakly exogenous. The $\chi^{2}$ statistic with three degrees of freedom is 5.32 and has a $P$-value of 0.15 , and the null hypothesis of the joint weak exogeneity of LRYdpc and LRp - LRpoil cannot be rejected. Thus, we will condition our model on these restrictions and reduce the VAR to a two-variable system.

\section{The short-run error correction model}

The vector obtained in the cointegration analysis represents the long-run relationship among the variables. To model the demand for electricity more generally, 
however, a short-run error correction model is employed. The error correction framework models the variables in differences; the coefficients on the differenced variables correspond to short-run elasticities. The model furthermore contains an error correction term $(\mathrm{ecm})$. This term is obtained from the long-run relationship and expresses deviations in electricity consumption from its long-run mean. The coefficient in front of the ecm term measures the speed of adjustment in current consumption to the previous equilibrium demand value. The model in its most general form is as follows:

$\Delta y_{t}=\alpha+\sum \delta_{i} \Delta y_{t-i}+\sum \beta_{i} \Delta x_{t-i}+\gamma \mathrm{ecm}_{t-1}+e_{t} \quad i=1, \ldots, t$

where $y$ are the dependent variables and $x$ is a vector of independent variables and $\mathrm{ecm}$ is the error correction term.

Boswijk and Franses (1992) emphasize that the dynamic specification can affect the size and power of the cointegration tests. We started by estimating a model in levels with three lags and used the BSC to reduce the number of lags. The results suggested that a single lag was adequate. However, theoretical grounds and individual $t$-statistics suggested that there may be additional explanatory power through three lags. This implies a model in first differences using only two lags. We retained two lags of each variable and then removed the insignificant regressors. Using the general-to-specific modeling approach, we finally obtained the results found in Table 4.

The equation of interest is DLkWhrpc, the change in the natural logarithm (or growth) of per capita consumption. The results for the change in urbanization are included as part of the system, but are not discussed because they are not the objective of the paper. Household disposable income and urbanization have positive and significant effects on residential electricity consumption, even in the short-run. The short-run vs. long-run elasticities are 0.23 vs. 1.04 for income and 1.61 vs. 3.91 for urbanization. Thus, as expected, the long-run elasticities are consistently higher.

The change in urbanization from the previous year has a positive effect on current consumption growth: a $1 \%$ increase in urbanization leads to a $1-2 \%$ increase in consumption still less than half the long-run effect. The urbanization measure was lagged one period since electricity consumption is not likely to react immediately to changes in its value. The positive effect may reflect Taiwan Power Corporation's requirement to serve customers, but also the greater propensity of urban residents to consume electricity than rural customers.

The own price of electricity was found to be inelastic, -0.15 , but not the relative price or the price of oil. The two latter variables did not provide any explanatory power to the model and were excluded from subsequent analysis. This is not as surprising as it may first seem: electricity in Taiwan is the only source for indoor cooling/heating, thus substitution possibilities are small. These, and more generally the fact that electricity is considered a basic consumption good, lend themselves as explanations for the low price elasticity. Branch (1993) finds short-run elasticities that are slightly larger for the US. 
Table 4

Final error correction representation of residential electricity demand sample: 1957-1995

\begin{tabular}{|c|c|c|c|c|}
\hline & Coefficient & Standard error & $t$-Value & $t$-Prob \\
\hline \multicolumn{5}{|l|}{ Equation for: DLkWhrpc } \\
\hline DLRp & -0.154172 & 0.05208 & -2.96 & 0.006 \\
\hline DLRYdpc & 0.225308 & 0.1016 & 2.22 & 0.034 \\
\hline Durban_1 & 1.60879 & 0.6592 & 2.44 & 0.021 \\
\hline ECM2_1 & -0.109377 & 0.03108 & -3.52 & 0.001 \\
\hline BudShr_1 & -5.07473 & 1.204 & -4.21 & 0.000 \\
\hline Cool $80^{-}$ & 0.0298176 & 0.009645 & 3.09 & 0.004 \\
\hline Constant, $U$ & 7.69323 & 1.857 & 4.14 & 0.000 \\
\hline \multicolumn{5}{|l|}{ Sigma $=2.56479$} \\
\hline \multicolumn{5}{|l|}{ Equation for: Durban } \\
\hline ECM2_1 & -0.0243385 & 0.005529 & -4.40 & 0.000 \\
\hline BudShr_1 & 0.553386 & 0.2613 & 2.12 & 0.043 \\
\hline DLRYdpc & -0.0437894 & 0.02140 & -2.05 & 0.050 \\
\hline Constant, $U$ & 0.556743 & 0.2973 & 1.87 & 0.071 \\
\hline \multicolumn{5}{|l|}{ Sigma $=0.572357$} \\
\hline Log-likelihood & -120.297587 & $-T / 2 \log \mid$ Omega $\mid$ & -9.62038176 & \\
\hline No. of observations & 39 & No. of parameters & 11 & \\
\hline LR test of over-identifying restrictions & \multicolumn{4}{|l|}{$\chi^{2}(7)=12.627[0.0817]$} \\
\hline \multirow{2}{*}{$\begin{array}{l}\text { DLkWhrpe } \\
\text { Durban }\end{array}$} & Portmanteau (5) & 9.96874 & & \\
\hline & Portmanteau (5) & 5.25935 & & \\
\hline DLkWhrpc & AR $1-2$ test & $F(2,28)=3.0466[0.0635]$ & & \\
\hline Durban & AR $1-2$ test & $F(2,28)=5.0529[0.0134]^{*}$ & & \\
\hline DLkWhrpc & Normality test & $\chi^{2}(2)=1.4092[0.4943]$ & & \\
\hline Durban & Normality test & $\chi^{2}(2)=8.6696[0.0131]^{*}$ & & \\
\hline DLkWhrpc & $\mathrm{ARCH} 1-1$ test & $F(1,32)=0.22808[0.6362]$ & & \\
\hline Durban & ARCH $1-1$ test & $F(1,32)=0.035284[0.8522]$ & & \\
\hline DLkWhrpc & Hetero test & $F(16,17)=1.4209[0.2398]$ & & \\
\hline Durban & Hetero test & $F(16,17)=0.37545^{2}[0.9718]$ & & \\
\hline
\end{tabular}


Cooling degree-day effects are important as well. The results using the $80{ }^{\circ} \mathrm{F}$ measure are reported. Similar results were obtained using the $74{ }^{\circ} \mathrm{F}$ measure. They suggest that a $1 \%$ increase in the number of days above $80^{\circ}$ leads to approximately a $3 \%$ increase in residential electricity consumption.

The error correction term is significant and has a coefficient of -0.11 , indicating that when demand is above or below its equilibrium level, consumption adjusts by one-tenth within the first year. There is a second 'correction' type term in the lagged expenditure share on electricity consumption. If the share increased last year, there is a significant downward effect this year.

The model overall has coefficients with the expected signs and with magnitudes that seem reasonable. The model also performs well statistically: more than a third of the annual variation of the change is explained, and the residual summary statistics for autocorrelation, conditional heteroskedasticity and normality do not reveal any problems.

The stability of the model is tested by examining model and parameter constancy through recursive estimation. Figs. 9 and 10 present the results from the tests. In the top two graphs of Fig. 9 we show the recursive residuals. The next two pairs contain one-step ahead and $n$-step-ahead Chow tests for the individual equations and the system, respectively. The first is equivalent to a sequence of 1-year ahead forecast tests and the second is a sequence of break point Chow tests. The test statistics are normalized on the critical values at 5\%. This implies that values greater than unity represent rejections of the null hypothesis of structural breaks. There are significant forecast errors in 1979 and 1981, but otherwise there do not appear to be any structural breaks (with 25-26 observations we might expect 1-2 rejections). In Fig. 10, the OLS recursive coefficient estimates and the associated two standard error bounds are plotted. The estimates are very stable.

\section{Conclusion}

We develop and estimate an error correction model of electricity consumption for a developing country, Taiwan, from 1955 through 1996. Our hypothesis is that the standard Fisher-Kaysen approach needs to be adapted for these countries. We have used a proxy variable, urbanization, to capture economic development characteristics and electricity-using capital stocks not explained by income. The variable provides significant explanatory power to the model both in the short-run and long-run. We have not seen this variable used in similar time series studies and we think it may hold promise in explaining residential electricity consumption in other developing countries.

Electricity consumption and urbanization are considered measures of economic development or part of the process. We tested for the null hypothesis of weak exogeneity for urbanization in the long-run system; it was rejected. Thus, we modeled residential electricity consumption and urbanization simultaneously to appropriately capture the dynamics of the relationship. Urbanization measured by the proportion of the population in cities of 100000 or more had positive long-run and short-run effects on consumption. 

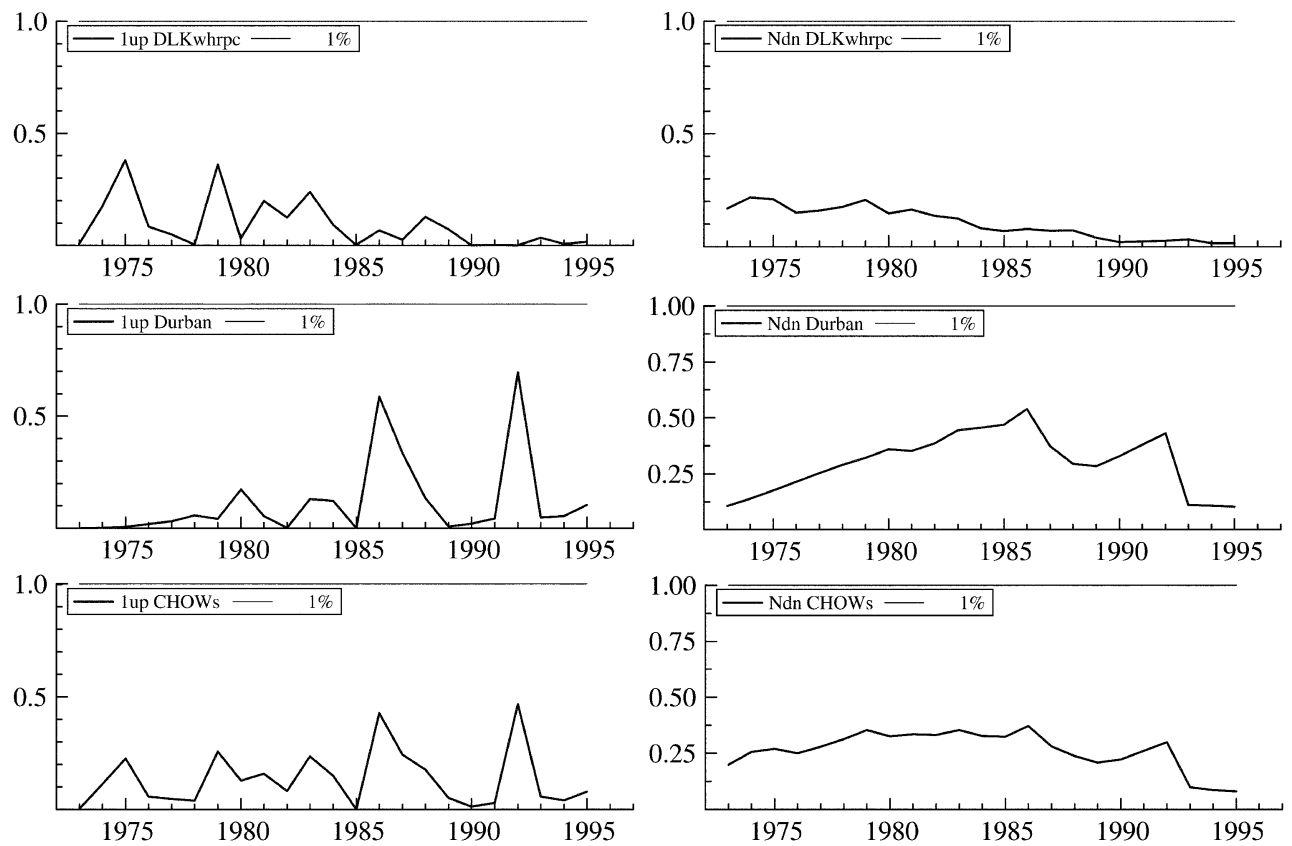

Fig. 9. Stability analysis of final error correction model (system) of residential electricity demand. The graphs in the left-hand column present the recursive 1-up Chow test for the electricity and urban equations and system, respectively. The stability test using the recursive Chow test is given in the three righthand graphs. 

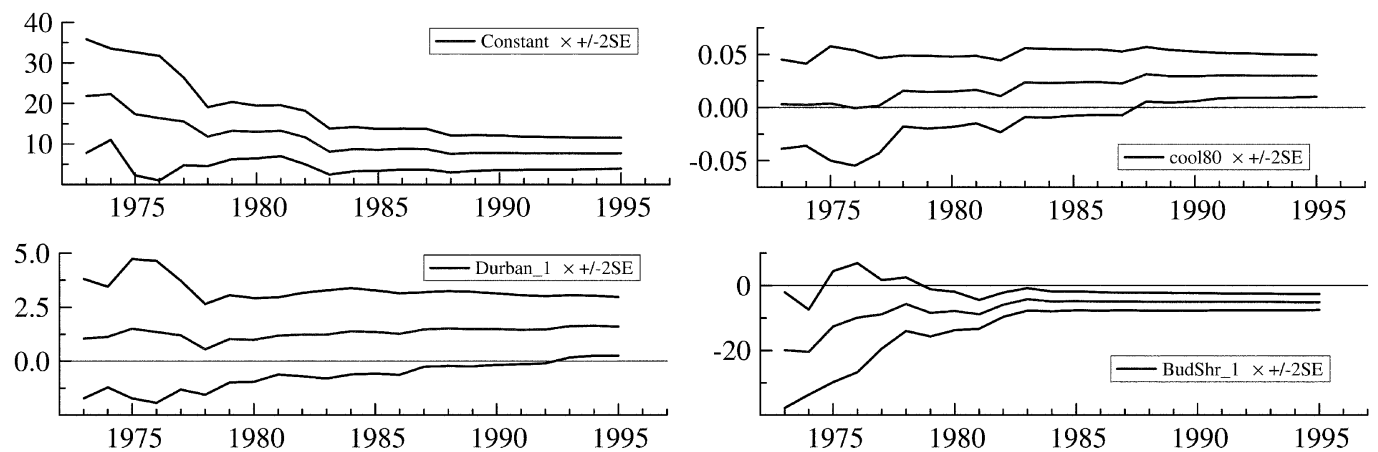

Fig. 10. Stability analysis of final error correction model of residential electricity demand recursive coefficient estimates with \pm 2 standard error bounds The recursive coefficient estimates with their two standard error bounds are given for the constant, cooling degree-days for $80^{\circ} \mathrm{F}$, the previous year's change in urbanization last year, the previous year's budget share for electricity last year, the current real price of electricity, the current change in income and the error or equilibrium consumption correction term. 
The income elasticity of residential demand is unity in the long-run. The relative price of electricity (to petroleum products) elasticity is inelastic in the long-run. Consistent with theory the short-run price elasticity of demand is more inelastic. Cooling degree-day effects have positive impacts on short-run demand.

The residential electricity demand model developed here is an attempt at understanding consumption in a (rapidly growing) developing country. Urbanization is an indirect measure of electricity-using capital stock and is subject to measurement error. As electricity use penetrates rural markets, the value of this measure may decline. However, in the case of Taiwan, the effect of urbanization and the model itself appear stable. The value and interpretation of urbanization measure(s) applied to other countries will depend on their institutions and history. The short-run income and price elasticities are smaller than the long-run elasticities, and thus are consistent with economic theory. The income elasticity appears to be unity in the long-run.

Electricity demand studies such as this one have important practical applications. The estimation of consistent and stable price- and income elasticity estimates are important. Government planners and private investors need to be well informed regarding the value of the market in privatization programs and investment projects in the electric utility sector. Admittedly, aggregate level and low frequency data are less preferred than their counterparts, but it is precisely the latter data that are the most difficult to obtain in developing countries. The estimates obtained in this study can therefore be viewed as providing good rules of thumb in the initial stage of investigation.

Taiwan is pursuing a privatization program for the electric utility sector. Thus, policy makers and private investors can benefit from the cointegration and error correction modeling techniques used in this paper. Note that this model's forecasting power has not been rigorously tested. This is an important topic for further research and a useful application of the elasticity estimates found here.

\section{Acknowledgments}

We have benefited from comments by Neil Ericsson, Julian Silk, Herman Stekler, seminar participants at the Colorado School of Mines, Charles River Associates, the US Energy Information Administration, and The George Washington University. Derek Bunn and an anonymous referee provided useful suggestions. In addition, $\mathrm{Mr}$ Tien-Sung Chien, Director of the Energy Commission of the Ministry Economic Affairs, Mr I.L. Wang and Stephen S.T. Lee, Directors of the General Planning Department at the Taiwan Power Company, were extremely helpful in responding to data requests and clarifications of the data. Chia-Hsin $\mathrm{Hu}$ and Christian Crowley provided research assistance. All errors and omissions remain with the authors.

\section{Appendix A: Data appendix}

The electricity consumption and price data for this study came from officials at the Taiwan Power Corporation and the Energy Commission in the Ministry of Economic Affairs. Mr I.L. Wang and Stephen S.T. Lee, successive Directors of the 
General Planning Department, provided data from the Taipower Annual Report (1996) and the Taipower Statistical Yearbook (1996). In some cases they translated consumption data tables from Chinese. Ms Cindy $\mathrm{Hu}$ collected historical and projected capacity and generation data from the Taiwan Power Company Annual Report, 1997. The demographic, disposable income and consumer price data came from the Taiwan Statistical Data Book, 1997. The world oil price data came from the US Annual Energy Review (1998) published by the US Energy Information Administration and the OECD International Energy Agency Statistics: Energy Prices and Taxes Q2 1997.

\section{References}

Bohi, D.R., Zimmerman, M., 1984. An update on econometric studies of energy demand. Annu. Rev. Energy 9, 105-154.

Boswijk, P., Franses, P.H., 1992. Dynamic specification and cointegration. Oxford Bull. Econ. Stat. 54 (3), 369-381.

Branch, R.E., 1993. Short run income elasticity of demand for residential electricity using consumer expenditure survey data. Energy J. 14 (4), 111-122.

Burney, N.A., 1995. Socioeconomic development and electricity consumption: a cross country analysis using the random coefficient method. Energy Econ. 17 (3), 185-195.

Campbell, J.Y., Perron, P., 1991. Pitfalls and opportunities: what macroeconomists should know about unit roots. In: Blanchard, O.J., Fischer, S. (Eds.), Macroeconomics Annual, vol. 6. MIT Press, Cambridge, MA.

Chien, T.-S., 1997, private correspondence.

Dahl, C., 1993. A survey of energy demand studies in support of the development of NEMS, prepared for the US Department of Energy.

Dahl, C., Erdogan, M., 1994. Oil demand in the developing world: lessons from the 1980s applied to the 1990s. Energy J. 15 (1), 69-78 Special Issue The Changing World Petroleum Market.

Doornik, J.A., Hendry, D.F., 1992. PCGIVE 7: An Interactive Econometric Modelling System. Institute of Economics and Statistics, University of Oxford, Oxford.

Engle, R., Granger, C.W.J., 1987. Cointegration and error-correction: representation, estimation and testing. Econometrica 55 (2), 251-276.

Espey, M., 1999. Turning on the lights: A meta-analysis of residential electricity demand analysis' Working Paper, University of Nevada at Reno.

Fisher, F.M., Kaysen, C., 1962. A Study in Econometrics: The Demand for Electricity in the United States. North-Holland Publishing Co, Amsterdam.

Halvorsen, R., 1975. Residential demand for electric energy. Rev. Econ. Stat. 57 (1), 12-18.

Harris, J.L., Lon-Mu, L., 1993. Dynamic structural analysis and forecasting of residential electricity consumption. Int. J. Forecasting 9, 437-456.

Hendry, D.F., 1986. Econometric modelling with cointegrated variables: an overview. Oxford Bull. Econ. Stat. 48 (3), 201-212.

Hendry, D.F., Juselius, K., 2000. Explaining cointegration analysis: Part I. Energy J. 21 (1), 1-42.

Hendry, D.F., Juselius, K., 2001. Explaining cointegration analysis: Part II. Energy J. 22, 75-120.

International Energy Agency Statistics: 1997. Energy Prices and Texes Q2.

Kokklenberg, E., Mount, T., 1993. Oil shocks and the demand for electricity. Energy J. 14 (2), $113-138$.

Lariviere, I., Lafrance, G., 1999. Modelling the electricity consumption of cities: effect of urban density. Energy Econ. 21 (1), 53-66.

MacKinnon, J.G., 1991. Critical values for cointegration tests. In: Engle, R.F., Granger, C.W.J. (Eds.), Long-Run Economic Relationship. Oxford University Press, Oxford, pp. 267-276.

Medlock III, K.B., Soligo, R., 2001. Economic development and end-use energy demand. Energy J. 22 (2), 77-105. 
Nelson, C.R., Peck, S.C., 1985. The NERC fan: a retrospective analysis of the NERC summary forecasts. J. Bus. Econ. Stat. 3 (3), 179-187.

Nelson, C.R., Plosser, C.I., 1982. Trends and random walks in macroeconomic time series: some evidence and implications. J. Monet. Econ. 10 (1), 139-162.

Nelson, C.R., Peck, S.C., Uhler, R.G., 1989. The NERC fan in retrospect and lessons for the future. Energy J. 10 (2), 91-107.

Osterwald-Lenum, M., 1992. A note with quantiles of the asymptotic distribution of the maximum likelihood cointegration rank test statistics. Oxford Bull. Econ. Stat. 54 (3), 461-472.

Plourde, A., Ryan, D., 1985. On the use of double-log forms in energy demand analysis. Energy J. 6 (4), 105-113.

Sheerin, J.C., 1992. Energy and economic integration in Thailand. Energy J. 13 (1), 145-156.

Taiwan Power Company Annual Report, 1997. Taipei, Republic of China.

Taiwan Statistical Data Book, 1997. Taipei, Republic of China.

Taylor, L., Blattenberg, G.R., Rennhack, R., 1984. Residential demand for energy in the United States: empirical results for electricity. In: Moroney, J.R. (Ed.), Advances in the Economics of Energy and Resources, vol 5. JAI Press, Greenwich, CT, pp. 85-102.

Tien-Sung Chien, 1997. Private correspondence.

US Annual Energy Review, 1998. Energy Information Administration, Department of Energy, Washington, DC.

Xiaohua, W., Zhenmin, F., 2001. Rural household energy consumption with the economic development in China: stages and characteristic indices. Energy Policy 29 (15), 1391-1397. 